\title{
Para Trazer o Emaranhado do Mundo ao Ensino de História
}

Gabriel Pereira de Oliveira ${ }^{1}$

\section{BOOK REVIEW}

WAKILD, Emily; BERRY, Michelle K. A Primer for Teaching Environmental History: Ten Design Principles. Durham \& London: Duke University Press, 2018. 


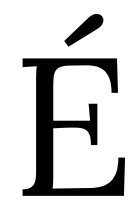

famosa em algumas áreas da América Latina a frase de Paulo Freire de que "ninguém educa ninguém, como tampouco ninguém educa a si mesmo: os homens se educam em comunhão, mediatizados pelo mundo". ${ }^{2}$ Em conjunto com a perspectiva de coletividade horizontal, Freire defendia a importância de incluir o "mundo", ou melhor, de partir dele, da vida vivida, para tecer as práticas educativas. Nesse sentido, pensar as aproximações entre tal princípio de Freire e o campo da História Ambiental parece ser um caminho bem interessante. Ao mostrar como a história humana não ocorre em um vazio, mas se faz em interação com o restante do mundo biofísico, a História Ambiental constitui uma perspectiva significativa para trazer o "mundo", com seu emaranhado de tramas entre humanos e não-humanos, aos processos de ensino e aprendizagem.

Um contributo valioso a esse empenho é o livro A Primer for Teaching Environmental History: Ten Design Principles, escrito sob autoria conjunta de Emily Wakild e Michelle Berry, publicado em 2018 pela Duke University Press. Esse livro tem como uma de suas marcas justamente a defesa de que a História Ambiental pode tornar a compreensão histórica mais palpável, com "passado e presente tangíveis" a partir das interações de humanos com a materialidade da vida na Terra. Ao incluir nas reflexões históricas aspectos não-humanos tão presentes em nosso cotidiano, mas nem sempre considerados pela historiografia, como outros animais e plantas, ou mesmo clima, solo e microrganismos patogênicos, a História Ambiental aprofunda o entendimento das próprias experiências humanas, desde suas relações de poder a questões de cultura e economia. Para as autoras, mais precisamente, "deixar o meio ambiente de fora da história significa imaginar que os seres humanos viveram em um mundo diferente desse" em que vivemos (p. 1-2).

Sob essa perspectiva de incluir nos processos educacionais as particularidades do mundo vivido, é preciso destacar que cada experiência educacional é única. As formas e condições para se "trazer o mundo" ao ensino nos Estados Unidos, obviamente, são por vezes bem distintas de muitas realidades latino-americanas. Não por acaso, Wakild e Berry tiveram o cuidado de enfatizar que "claramente nem todas as nossas estratégias servirão em todos os lugares ou com todos os estudantes" (p. XI).

\footnotetext{
${ }^{2}$ Paulo Freire. Pedagogia do Oprimido (Rio de Janeiro: Paz e Terra, 2005), 79.
} 
Wakild e Berry, então, oferecem em seu livro não um modelo replicável, algo como uma receita de bolo com instruções a serem estritamente seguidas. Em vez disso - e de modo muito mais interessante, vale dizer -, A Primer for Teaching Environmental History se propõe a pensar o ensino de História Ambiental a partir justamente da partilha de vivências das autoras. E, mais do que apenas duas pessoas relatando seus cotidianos, algo que dá um tom de beleza muito especial à obra é o caráter coletivo de sua escrita e reflexão, fruto da amizade e experiências de ensino compartilhadas entre as autoras. Isso confere ao livro não somente uma leitura bastante agradável, mas também torna a obra um mundo de inspirações a partir do encontro com outras realidades.

O livro, mais especificamente, está organizado em três partes, que, ao todo, oferecem dez capítulos ou princípios para pensar o ensino de História Ambiental. Na primeira seção, intitulada Approaches, há quatro capítulos com sugestões para introduzir a História Ambiental e mostrar sua relevância a partir de aspectos concretos do dia-a-dia como alimentos, animais, mobilizações sociais, frutas, crise climática. A segunda parte, Pathways, lança novos olhares a partir da História Ambiental a temas como ciência, relações de espacialidade e as tramas de poder, em especial nas disputas quanto à água e energia. Já em Applications, que é a última parte do livro, as autoras analisam experiências de ensino de História Ambiental a partir de noções de desigualdade social e justiça ambiental, bem como tratam também da elaboração de avaliações e do uso de ferramentas tecnológicas na educação de gerações de estudantes cada vez mais conectadas à internet.

A obra se destina principalmente a professores, seja de universidades e cursos acadêmicos em geral, seja de escolas para crianças e adolescentes. É certo que as experiências das autoras proporcionam um contributo rico a quem busca montar cursos específicos de História Ambiental. Ao mesmo tempo, contudo, o livro trata também de possibilidades de, a partir do diálogo com a História Ambiental, repensar abordagens históricas e cursos já existentes. Isso é muito importante sobretudo para que as discussões do livro possam alcançar professores sem familiaridade com a História Ambiental, a quem a leitura do livro também é recomendada. 
Vale a pena ressaltar, ainda mais em uma resenha para a HALAC, que o livro traz alguns aspectos mais específicos relativos à América Latina. Especialmente a experiência de Emily Wakild, especialista em História da América Latina, foi muito importante para reflexões a partir de temas como a agricultura ou o clima no México, ou para o momento de campo com estudantes em viagem ao Peru (ver capítulo 5).

Aliás, é preciso dizer que essa obra foi publicada também em uma versão em espanhol, lançada em 2020, em co-edição da Pontificia Universidad Católica de Chile com a Duke University. ${ }^{3}$ Isso é bastante emblemático não somente da excelente qualidade do livro, mas também de como a obra vem à tona em um momento de consolidação da História Ambiental, inclusive na América Latina, com uma maior presença de historiadores ambientais tanto em universidades como em escolas. ${ }^{4}$

Por fim, se o livro consiste em uma partilha de experiências de ensino, eu me atrevo a prosseguir esse diálogo compartilhando que, para mim, foi fantástico conhecer as vivências de Wakild e Berry enquanto eu planejava aulas para turmas de adolescentes no semiárido brasileiro, ainda mais em um contexto de pandemia. Sobretudo nesse momento de crise ambiental, em especial em sua face climática, a História Ambiental se mostra cada vez mais fundamental, seja nos espaços de ensino e pesquisa ou fora deles. E, se a educação é comunhão a partir do mundo vivido, como bem disse Paulo Freire, o diálogo com as experiências de Wakild e Berry pode ser bastante inspirador para nos mobilizarmos frente aos desafios do nosso tempo.

\footnotetext{
${ }^{3}$ Emily Wakild and Michelle K. Berry. Una Guía para la Enseñanza de Historia Ambiental: Diez Principios de Diseño (Santiago: Ediciones UC, Duke University Press, 2020).

${ }^{4}$ Claudia Leal. Aguzar la mirada colectiva, el gran desafío de la historia ambiental latinoamericana. Historia y Sociedad, 36 (Ene-Jun 2019): $243-$ 268. Além das discussões em encontros como os simpósios da Sociedad Latinoamericana y Caribeña de Historia Ambiental (SOLCHA), um caso mais específico na América Latina que posso citar, por conhecer mais de perto, são as discussões no Brasil, onde há experiências como as atividades do Laboratório Virtual de Ensino de História (https://lveh.webnode.com/) e do Mestrado Profissional em Ensino de História da Universidade Federal do Pará, campus de Ananindeua; do Laboratório de História e Natureza na Universidade Federal do Rio de Janeiro (LabHeN - UFRJ) (https://www.youtube.com/channel/UCsYFWs25StDwj73nWKqX5kw); do projeto Educação Ambiental no Ensino de História (http://www.fafich.ufmg.br/hea/) e do programa As quatro estações (https://www.youtube.com/channel/UCEOC9XfCxfF6O08_TzqtgEA), na Universidade Federal de Minas Gerais; além do dossiê organizado por Elenita Malta Pereira: História Ambiental e Ensino. Revista do LHISTE. Porto Alegre. 6, 4 (Jan-Dez 2017).
} 


\section{REFERÊNCIAS}

Claudia Leal. Aguzar la mirada colectiva, el gran desafío de la historia ambiental latinoamericana. Historia y Sociedad, 36 (Ene-Jun 2019): 243-268.

Elenita Malta Pereira (org). História Ambiental e Ensino (dossiê). Revista do LHISTE. Porto Alegre. 6, 4 (Jan-Dez 2017).

Emily Wakild and Michelle K. Berry. A Primer for Teaching Environmental History: Ten Design Principles (Durham \& London: Duke University Press, 2018).

. Una Guía para la Enseñanza de Historia Ambiental: Diez Principios de Diseño (Santiago: Ediciones UC, Duke University Press, 2020).

Paulo Freire. Pedagogia do Oprimido (Rio de Janeiro: Paz e Terra, 2005). 